\title{
A note on the St. Petersburg paradox
}

\author{
Shrisha Rao \\ Shrisha Rao's major academic interest is in the area of safety in distributed com- \\ puter systems - what constitutes a safe distributed system, and how can we create \\ distributed systems that are safe? The motivation behind this is easy to realize; the \\ world of computing is increasingly distributed, with resources that are geographi- \\ cally spread, often with no central authority or assurances of performance. Tasks and \\ services that a single person uses are increasingly likely to depend upon invocations \\ of resources that are distributed. The safety of persons or property may also depend \\ upon the proper functioning of diverse, uncorrelated computing elements. In his \\ spare time, he volunteers for the American Red Cross - he is a certified instructor \\ in First Aid and CPR, and is also trained in various disaster relief tasks.
}

\section{Introduction}

The St. Petersburg paradox is said to occur when we express our unwillingness to take up someone's offer of a game under the following conditions: Assume that someone offers to toss a fair coin repeatedly, with a fixed investment by us to play the game, where we stand to win 1 unit of money should the first toss turn up heads, 2 if the second should turn up heads, and 2 raised to $(n-1)$, should the $n$th toss turn up heads. The game ends at the first heads obtained.

Our expectation in playing the game has to be, by the laws of probability, the sum of an infinite sequence, where each term in the sequence is the product of the possible gain from a certain occurrence of heads, and the probability that a given toss will be the first one to turn up heads, or a total of

$$
\left(1 \cdot \frac{1}{2}\right)+\left(2 \cdot \frac{1}{4}\right)+\left(4 \cdot \frac{1}{8}\right)+\ldots=\frac{1}{2}+\frac{1}{2}+\frac{1}{2}+\ldots=\infty .
$$

In dem nachfolgenden Beitrag geht es um ein Problem der Wahrscheinlichkeitstheorie. In einem Spiel beschreibt der Erwartungswert den durchschnittlichen Gewinn auf lange Sicht. Bei einem fairen Spiel richtet sich der Einsatz folglich nach dem Erwartungswert. Beim „Petersburger Spiel“ ist nun der Erwartungswert unendlich gross. Dementsprechend müsste man bereit sein, jeden beliebig hohen Einsatz für die Teilnahme an diesem Spiel zu zahlen. Dennoch wird man kaum Interessenten finden, die einen nennenswerten Betrag dafür ausgeben würden. Eine scheinbar paradoxe Situation? Auf den folgenden Zeilen unterbreitet der Autor einen Vorschlag zur Auflösung dieses „Paradoxons“. $j k$ 
The paradox is that we can hardly expect to find anyone willing to play the game under the stated conditions; if such were offered to us, we would not be willing to invest our life's savings to play it, although the theoretical expectation is infinity. To paraphrase d'Alembert ([2]), "no one would be willing to pay even a modest amount of money to enter this game, not to mention an infinite amount." The problem therefore is to justify this widespread behavior, which is contrary to known and accepted laws of probability, which would require us to accept offers of games where the expectation is (much) larger than the investment.

The most common approach to arrive at a justification dates to Bernoulli ([1]), and invokes utility theory, to say that there is a "moral expectation" that does not rise linearly over an infinite range with rising expectation, but rather rises asymptotically to a finite peak value. This is a somewhat sensible explanation, but suffers from the fallacy of being rather ad hoc, as though tailored to fit this one problem, and also relies on the often-unstated axioms of utility theory ([3], [4]).

\section{A solution to the paradox}

To arrive at a solution, we start by noting that it makes no sense to speak of an infinite expectation of return on any investment, no matter what the theoretical value of the same, because the world's (or even the observable universe's) resources are known to be finite, and all our thinking should rightly take this into account. That is to say, we should know for sure that given that there is only a finite amount of money in the world, no statement by anyone offering us a game with an infinite return is credible for this very reason. Given this constraint of finiteness, the paradox disappears; to see how, just consider the following.

Let us say that the person offering the game has a total amount $M$ of money available. Then, we can only play the game as long as the person offering can still repay us, should there be an occurrence of heads then. Since the rules of the game call for us being paid $2^{n-1}$ for an occurrence of heads on the $n$th toss, this means that the game can only go on for so long as:

$$
2^{n-1} \leq M
$$

Since the return from a bounded sequence of any $r$ number of tosses is exactly $\frac{1}{2} \cdot r$, if we are to invest in a way such that our expected return matches or exceeds our investment, we can invest an amount $m$ to play the game only if:

$$
\frac{n}{2} \geq m
$$

Taken together, these inequalities give:

$$
M \geq 2^{2 m-1} .
$$

We also may note that the number of tosses $n$ that may be supported grows only as the logarithm of the money $M$ available to the person offering the bet:

$$
n \leq\left\lfloor\log _{2} M\right\rfloor+1 \text {. }
$$


Therefore, the sum $M$ that is required on the part of the person offering the game grows exponentially, with increasing $m$, the amount of money we are prepared to invest, and is also exponential on $n$, the number of tosses for which the game is meaningful; for us to invest $\$ 10$ to play this game, the person offering must have at least $\$ 524288$ invested in it! This is the correct explanation for why, as d'Alembert points out, no one is willing to invest even modest sums to play such a game. The exponential growth of $M$ with increasing $m$ means that even with an investment of just $\$ 50$, the amount of money required on the part of the person offering the game is over $\$ 6.33 \cdot 10^{29}$, which is much greater than the total amount of money available in the world.

Acknowledgements. The author wishes to thank David Banks and Petros Hadjicostas for interesting discussions on the topic of this paper, and the Editor and the anonymous referee for helping clarify the presentation of his ideas.

\section{References}

[1] Bernoulli, D.: Specimen theoriae novae de mensura sortis. Commentarii Academiae Scientiae Imp. Petropolitanae, V, 1738, 175-192. English translation in Econometrica 22 (1954), 23-36.

[2] d'Alembert, J.: Réflexions sur le calcul des probabilités, in: Opuscules Mathématiques, vol. 2, Paris 1761, $1-25$.

[3] Jeffreys, H.: Theory of Probability, Third Edition, Oxford University Press 1961, 31-32.

[4] Maistrov, L.E.: Probability Theory: A Historical Perspective, Academic Press 1974, 106, 116, $125-129$.

\section{Shrisha Rao}

University of Iowa

Department of Computer Science

14 MacLean Hall

Iowa City, IA 52242, USA

e-mail: srao@cs.uiowa.edu 